\title{
Speech-language-hearing follow-up of preterm children: feeding and neuropsychomotor performance
}

\author{
Larissa Mayra Rossigali de Jesus ${ }^{1}$ \\ https://orcid.org/0000-0002-4283-0542 \\ Caroline Stefani Dias Basso ${ }^{2}$ \\ https://orcid.org/0000-0002-9951-6829 \\ Lilian Castiglioni ${ }^{3}$ \\ https://orcid.org/0000-0002-9999-2673 \\ Adriana Lucia Monserrat ${ }^{4}$ \\ https://orcid.org/0000-0002-0050-313X \\ Marta Alves da Silva Arroyo ${ }^{5}$ \\ https://orcid.org/0000-0002-5862-3396
}

Faculdade de Medicina de São José do Rio Preto, São José do Rio Preto, São Paulo, Brasil.

Hospital da Criança e Maternidade de São José do Rio Preto, São José do Rio Preto, São Paulo, Brasil.

Faculdade de Medicina de São José do Rio Preto, Departamento de Epidemiologia e Saúde Coletiva, São José do Rio Preto São Paulo, Brasil. Hospital da Criança e Maternidade de São José do Rio Preto, Residência Multiprofissional da Saúde da Criança, São José do Rio Preto, São Paulo, Brasil.

Faculdade de Medicina de São José do Rio Preto, Residência Multiprofissional em Saúde da Criança, São José do Rio Preto, São Paulo, Brasil.

Conflict of interests: Nonexistent

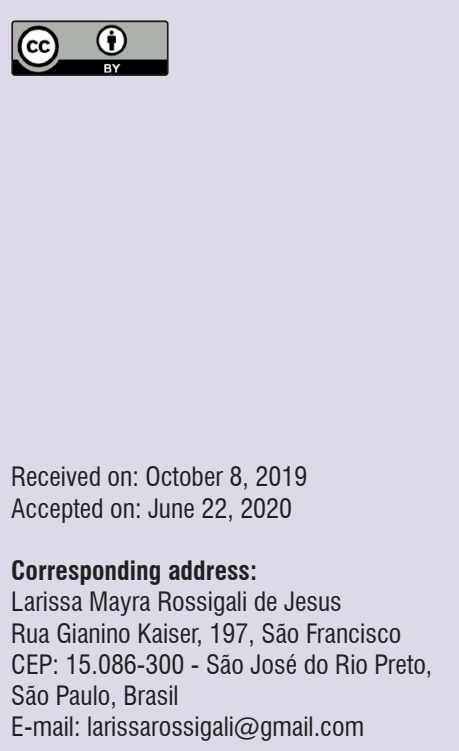

\section{ABSTRACT}

Purpose: to establish the breastfeeding rates at hospital discharge and post-discharge, analyze neuropsychomotor development, and indicate the rehabilitation referral rate of preterm children attended by speech-language-hearing therapists.

Methods: a total of 39 preterm children participated in the study. They were born at a Children and Maternity Hospital between August 2016 and January 2017 and were followed up by the speech-language-hearing therapists during the hospital stay. The Spearman's statistical test was used. The p-value was set at 0.005 ; the correlation value was: $r=0.10$ to 0.39 , weak correlation; $r=0.40$ to 0.69 , moderate correlation; and $r=0.70$ to 1 , strong correlation.

Results: of the 39 participants, 17 (43.6\%) were discharged on exclusive breastfeeding; 4 (10.25\%), on mixed milk feeding (breast and cup); 14 (35.9\%), on mixed milk feeding (breast and baby bottle); and 4 (10.25\%), on artificial milk feeding - baby bottle. After introducing solid food, $12.8 \%$ remained on breastfeeding, $38.4 \%$ on mixed milk feeding, and $48.7 \%$ in artificial milk feeding. Complementary feeding was introduced at 5 months (adjusted age). Auditory, motor and language development occurred as expected in $90 \%$ of the children, considering the milestone's adjusted age.

Conclusion: at hospital discharge, most infants were on exclusive or mixed breastfeeding. After discharge, mixed breastfeeding lasted longer, and low neuropsychomotor development impairment rates and rehabilitation referral rates were observed.

Keywords: Newborn; Breastfeeding; Child Health Services; Speech, Language and Hearing Sciences 


\section{INTRODUCTION}

The scientific advances in neonatology in the last decades brought about great changes in newborn assistance, leading to a significant increase in the survival rate of both preterm and low birth weight newborns, as well as of those who had serious complications. Nevertheless, as increasingly younger and smaller babies survive, the morbidities faced by them as they grow up also appear'.

These children can have important sequelae, such as chronic and neurologic diseases, learning difficulties, and cognitive, language, sight, hearing, and behavioral disorders ${ }^{2}$. These complications can cause short- and long-term development alterations ${ }^{1}$.

The newborn's (NB) oral feeding requires that their oral reflexes be preserved; however, these are oftentimes absent or inadequate in preterm newborns (PTNB). They are divided into defense reflexes (which are necessary to ensure protection during oral feeding) and feeding reflexes. They provide information on the neurological functioning of the oral motor structures, indicating whether the child has the neurological components necessary for feeding ${ }^{3}$.

The sucking reflex is characterized as an innate reflex, controlled by the pons and spinal cord. The precise moment when it is formed varies from author to author and is observed between the $15^{\text {th }}$ and $16^{\text {th }}$ gestational weeks ${ }^{4}$.

Sucking is a function of the stomatognathic system ${ }^{5}$ involving the coordinated work of the tongue, hyoid bone, mandible muscles, and lower lip. The coordination of the sucking, breathing, and swallowing functions take place between the $32^{\text {nd }}$ and $34^{\text {th }}$ gestational weeks ${ }^{6}$ - the swallowing reflex, which appears between the $13^{\text {th }}$ and $14^{\text {th }}$ gestational weeks, is one of the most important reflexes ${ }^{7}$.

The survival of some PTNB in the most critical period, when they cannot feed orally, depends on alternative routes. Hence, they can be fed parenterally, enterally, through an orogastric or nasogastric probe, or gastrostomy.

Breastfeeding has many benefits for the mother and baby. It favors the development of the stomatognathic functions, as sucking the breast offers an adequate stimulation for the orofacial muscles ${ }^{9,10}$.

By six months old, the development stage reached by the child includes physiological and neurological maturation of the organs, oral and global motor development, and attenuation of the tongue extrusion reflex
- which makes it easier for them to swallow creamy foods and accept the spoon ${ }^{11}$.

According to the shared follow-up approach involving the hospital and primary health care (Kangaroo Method Manual) ${ }^{12}$, the neuropsychomotor development takes place in predictable and preestablished stages - milestones, in the head-tail direction and from the center to the periphery ${ }^{13}$. This manual proposes that in cases of prematurity their chronological age be adjusted until they are two years old ${ }^{12}$.

Thus, this study is expected to contribute to the field of speech-language-hearing sciences, showing the importance of this professional both in the hospital and outpatient services to maintain breastfeeding, safely and adequately introduce complementary feeding, and early detect auditory, motor, and language development alterations.

Therefore, this study aimed to establish the breastfeeding rates at hospital discharge and post-discharge, analyze the neuropsychomotor development, and indicate the rehabilitation referral rate of preterm children attended by speech-language-hearing therapists.

\section{METHODS}

This retrospective documentary study collected data from the electronic medical records of 39 preterm children born between August 2016 and January 2017 at the Hospital da Criança e Maternidade (HCM) who met the inclusion criteria. It was approved by the Research Ethics Committee of the Faculdade de Medicina de São José do Rio Preto - FAMERP, São José do Rio Preto, SP, Brazil, under evaluation report number 2.739.601.

The inclusion criteria were: PTNB (less than 37 gestational weeks); low birth weight (under $2.5 \mathrm{Kg}$ ); hospitalized in the Neonatal Intensive Care Unit or Neonatal Intermediate Care Unit; attended with the Kangaroo Method and by the speech-languagehearing service during hospital stay; and undergoing speech-language-hearing follow-up at the specialized outpatient center of the Hospital de Base.

The exclusion criteria were: syndromes, severe neonatal anoxia, congenital malformations, PT or low weight NB who did not need neonatal intensive care, and PTNB who could not breastfeed and/or were contraindicated to it, due to causes inherent to the NB's.

Two PTNB whose mothers were HIV-positive, and whose breastfeeding was contraindicated, were 
included in the study because of outpatient follow-up, the introduction of solid foods, and auditory, motor, and language development.

The data were obtained from the participants' medical records and analyzed according to clinical history variables, such as gender, Apgar, gestational age, birth weight (for these last two, the classification proposed by the World Health Organization ${ }^{14}$ was considered), and orotracheal intubation time. Data regarding breastfeeding at the hospital discharge and post-discharge were analyzed, as well as its duration and the time when complementary feeding was introduced.

Both the reference data and the neuropsychomotor and language development data were obtained from a development follow-up sheet based on the following instruments: Denver Developmental Screening Test ${ }^{15}$, GESELL $^{16}$, and the Child Health Booklet ${ }^{17}$ from the Brazilian Ministry of Health.

Solid food was introduced in the sample as recommended by $\mathrm{WHO}^{14,18}$ and the Kangaroo Method ${ }^{12}$ - creamy consistency fruit is the most indicated and consequently the most recurrent. Soon after the adaptation period, they were instructed to move on to salty creamy meals.

The infants underwent audiological examinations and auditory development follow-up, whose data were collected. The audiological examinations performed were the otoacoustic emissions (infant hearing screening test), brainstem auditory evoked potentials (BAEP), and auditory screening with various instruments (drum, big and small agogo iron bells, bell, and different types of rattle).

The infant hearing screening test was conducted after hospital discharge, while the BAEP was performed at the chronological age of 12 months. The auditory screening was done in their follow-up visits in the speech-language-hearing sector, at different chronological ages - NB (up to 28 days of life), 1 month, 3 months, 6 months, 8 months, 10 months, 12 months, and 18 months.

All the participants, as their development was at risk, were referred to outpatient follow-up with the following specialties: pediatrics, otorhinolaryngology, ophthalmology, neurology, speech-language-hearing therapy, and physical therapy. This is a routine procedure for all premature newborns. However, not all participants were assessed by all specialties, as the adherence depends on the parent/guardian returning with the child for the follow-up visit.

The individual care referral rate of children who had development alterations was researched, regarding the rehabilitation services in the fields of speech-languagehearing, physical therapy, and occupational therapy.

Initially, the results were presented with descriptive analysis; afterward, with inferential analysis. For statistical analysis, the IBM SPSS (Statistical Package for Social Sciences) software, version 23.0 was used. The significance level was set at $5 \%$. Spearman correlation statistical test was used to verify the relationship between the qualitative variables, such as gestational age (GA) correlated with the orotracheal intubation time (OIT), and GA and birth weight and their correlation with the breastfeeding rate after hospital discharge, as well as its duration.

Spearman's correlation coefficient $(r)$ ranges from -1 to 1 . The sign indicates the positive or negative direction of the relationship, while the value suggests the strength of the relationship between the variables. A perfect correlation (-1 or 1 ) indicates that a variable's score can be precisely established once the other's score is known.

Authors $^{19}$ point to the following classification: $r=0.10$ to 0.39 (weak correlation), $r=0.40$ to 0.69 (moderate correlation), and $r=0.70$ to 1 (strong correlation).

\section{RESULTS}

Regarding the birth data, of the 39 infants, 25 $(64.1 \%)$ were males and 14 (35.9\%), females. The mean GA was 31 weeks; mean birth weight, 1.400 grams - $19(48.7 \%)$ were considered low birth weight PTNB, 15 (38.5\%) very low birth weight PTNB, and 5 (12.8\%) extremely low birth weight PTNB, following the classification proposed by $\mathrm{WHO}^{15}$ (Figure 1).

Regarding the conditions at birth, the mean one-minute Apgar score was 7, and the five-minute, 9.

The mean orotracheal intubation time was six days. The Spearman correlation test showed the influence of the GA regarding the OIT, as there was a moderate negative correlation $(r=-0.609$ and $p=<0.0001)$. 


\begin{tabular}{|c|c|}
\hline & Sample characterization \\
\hline Gender & $64.1 \%$ males \\
& $35.9 \%$ females \\
\hline \multirow{2}{*}{ Race } & $92.31 \%$ white \\
& $5.13 \%$ multiracial \\
\hline Gestational age (mean) & $2.56 \%$ not mentioned \\
\hline Classification & 31 weeks \\
\hline One-minute Apgar (mean) & $48.72 \%$ low birth weight newborn \\
\hline Five-minute Apgar (mean) & $38.46 \%$ very low birth weight newborn \\
\hline Orotracheal intubation & $12.82 \%$ extremely low birth weight newborn \\
\hline Days of orotracheal intubation (mean) & 7 \\
\hline
\end{tabular}

Figure 1. Sample characterization with demographic and clinical data

At discharge, the 39 children were on different types of milk feeding - 17 (43.60\%) were discharged on exclusive breastfeeding (EBF), 4 (10.25\%) on mixed milk feeding (breast and formula in a cup), 14 (35.90\%) on mixed milk feeding (breast and formula in a baby bottle), and 4 (10.25\%) on artificial milk feeding (baby bottle). Of the four children who were discharged on artificial feeding, two were contraindicated for breastfeeding because their mothers were HIV-positive (Figure 2).

\begin{tabular}{|c|c|}
\hline \multirow{3}{*}{ Milk feeding rates at hospital discharge } & $43.60 \%$ exclusive breastfeeding \\
& $10.25 \%$ mixed milk feeding (breast + cup) \\
\hline \multirow{2}{*}{ Milk feeding continuity rates after hospital } & $35.90 \%$ mixed milk feeding (breast + baby bottle) \\
discharge and the introduction of solid food & $10.25 \%$ artificial milk feeding - baby bottle \\
\hline & $12.82 \%$ breastfeeding \\
& $38.46 \%$ mixed milk feeding \\
Duration of milk feeding continuity after hospital & $48.71 \%$ artificial milk feeding \\
\cline { 2 - 2 } discharge and the introduction of solid food (in & Breastfeeding \\
months) & Minimum: 1 month \\
& Mean: 4 months \\
& Maximum: 8 months \\
\hline & Mixed milk feeding \\
& Minimum: 3 months \\
& Mean: 6 months \\
\hline
\end{tabular}

Figure 2. Milk feeding rates at hospital discharge, after hospital discharge, and after the introduction of solid food 
Regarding the continuity of milk feeding after solid food had been introduced, $12.8 \%$ of the children continued breastfeeding, $38.5 \%$ remained on mixed milk feeding, and $48.7 \%$ remained in artificial milk feeding. The mean duration of milk feeding after hospital discharge was also verified; EBF lasted four months on average, while mixed milk feeding lasted six months on average (Figure 2).
Figure 3 shows the correlation between gestational age and exclusive breastfeeding (GA $\times \mathrm{EBF}$ ), gestational age and duration of breastfeeding (GA $x$ duration of breastfeeding), birth weight $x$ exclusive breastfeeding (BW $\times \mathrm{EBF})$, and birth weight and duration of breastfeeding (BW $x$ duration of breastfeeding)

\begin{tabular}{|l|c|c|c|}
\hline Variables & P-value & R-value & Type of correlation \\
\hline GA x EBF & 0.0191 & 0.3738 & Weak positive \\
\hline GA x duration breastfeeding & 0.3896 & -0.2478 & Weak negative \\
\hline BW $\times$ EBF & 0.0184 & -0.3756 & Weak negative \\
\hline BW $\times$ duration breastfeeding & 0.9352 & 0.02367 & Weak positive \\
\hline
\end{tabular}

Figure 3. Correlation with the Spearman's test between gestational age and birth weight with the breastfeeding rates

Complementary food was introduced at the mean age of five months, considering the adjusted age - the minimum age was three months, and the maximum, nine months.
According to Figure 4, the mean age found for the motor and language development milestones was the expected, considering the adjusted age.

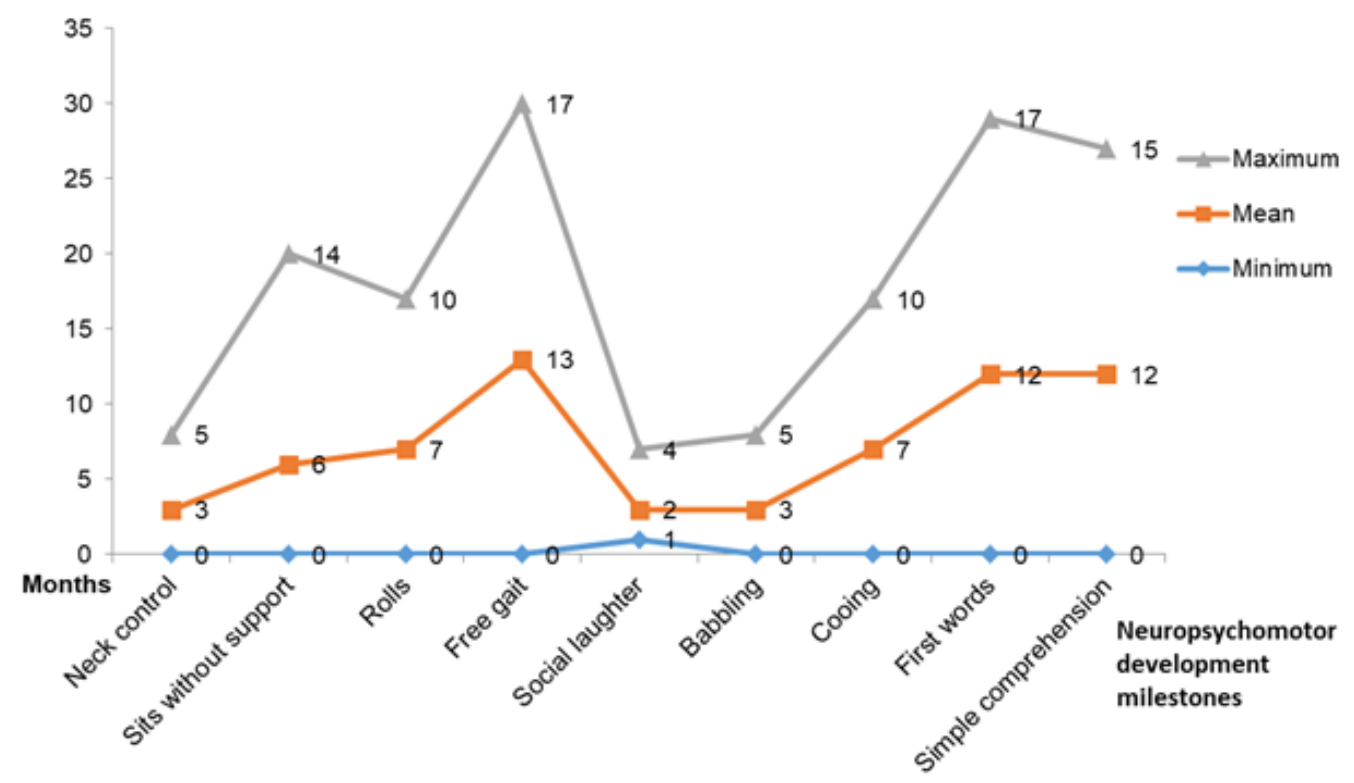

Figure 4. Motor and language development at an adjusted age 
Figure 5 shows that most of the children presented adequate neuropsychomotor development, according to the expected for this development milestone's adjusted age.

Regarding auditory development, a great part of the children underwent evoked otoacoustic emissions (EOAE) (infant hearing screening test), brainstem auditory evoked potentials (BAEP), and auditory development follow-up with auditory screening, as shown in Figure 6. Most of the children's auditory development and hearing were within normality standards. Of the 39 children, 10 did not perform the BAEP because they did not attend the examination.

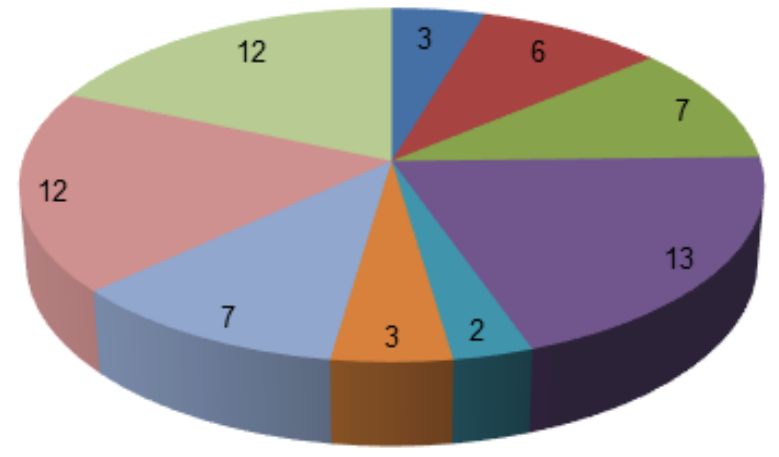

Months

\author{
- Neck control \\ - Sits without support \\ - Rolls \\ - Free gait \\ - Social laughter \\ Babbling \\ m Cooing \\ - First words \\ - Simple comprehension
}

Figure 5. Mean adjusted age for language and auditory development milestones

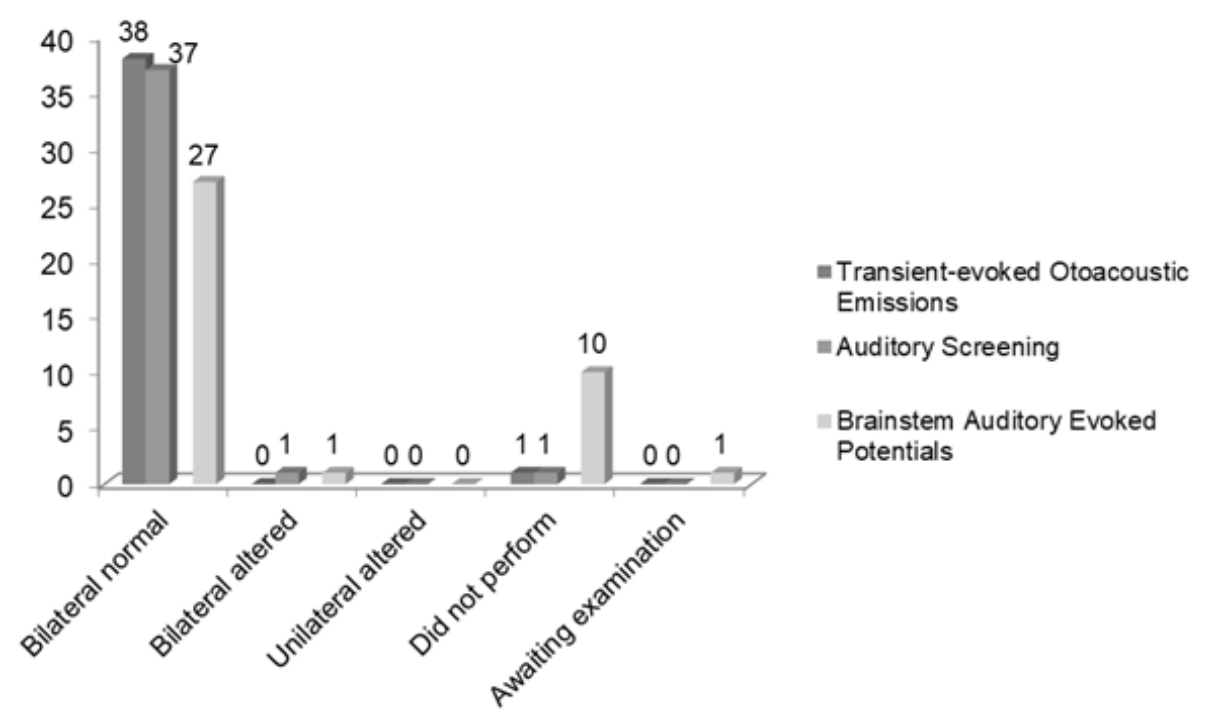

Figure 6. Auditory examinations

As for adherence, of the 39 children, 29 (74.3\%) attended the follow-up with the specialties, whereas 10 $(25.7 \%)$ were not taken to the scheduled visit by their parents/guardians.

Regarding the rehabilitation referral rates, it was verified that $20.5 \%$ (8 children) needed such referrals in the fields of physical therapy and occupational therapy.

\section{DISCUSSION}

The mean OIT in this study was six days. Authors ${ }^{20}$ reported higher breastfeeding rates in children who did not need OIT. In a study ${ }^{21}$, researchers stated a possible influence of the use of orotracheal tube on the oral skills of preterm children and concluded that these children took more time to reach full orality.

Most of the infants were discharged on breastfeeding. The EBF rates found in this study were similar to those of a study conducted at a child-friendly 
hospital, which follows routines and practices aimed at promoting breastfeeding ${ }^{22}$. It should be noted that the hospital where the present study was conducted is not an accredited child-friendly hospital.

A study reports higher breastfeeding rates than those found in this study - most of LWNB were discharged from the hospital and outpatient care at the third stage of the Kangaroo on $\mathrm{EBF}^{23}$. In the institution, the Kangaroo Method is in its implementation phase; hence, the third stage of the method is not offered, only multiprofessional follow-up of the PTNB with risk factors for growth and development alterations.

The PTNB are part of a group with high early weaning rates. The difficulties in breastfeeding can be explained by the countless factors involving the baby and its family. Due to its immature brain, at the time of breastfeeding the PTNB may find it difficult to stay awake and get organized; they may also show few signs of being hungry/thirsty, get fussy and stressed, and even have weak oral reflexes ${ }^{12}$.

Authors observed lower breastfeeding rates at hospital discharge when compared with the results of the present study - with $5.5 \%$ for EBF; $65.8 \%$ for mixed milk feeding; $28.6 \%$ for artificial milk feeding. After the hospital discharge, at the age of one month, $81.3 \%$ were breastfeeding, which decreased to $68.5 \%$ at the age of two months, $62.4 \%$ at three months, $48.1 \%$ at four months, and $22.4 \%$ at six months (adjusted age). The median breastfeeding duration was four months ${ }^{24}$ - the same found in this study (Figure 2). A study found a mean breastfeeding duration of five months; also, 2.6 times more preterm infants with less than 32 weeks weaned early when compared with those born at 32 weeks or more ${ }^{25}$.

The removal of the probe and transition to oral feeding must be encouraged as soon as possible. Using the probe for three weeks or more can have consequences, such as oral hypersensitivity, choking, biting, crying, and an increase in the incidence of gastroesophageal reflux ${ }^{3}$.

The mean adjusted age when complementary food was introduced in this study was five months (minimum age three months and maximum, nine months). Few studies were found in the reviewed literature regarding the age when complementary food was introduced in preterm infants. Child complementary feeding must start at six months old in cases of full-term newborns, as instructed by the Brazilian Ministry of Health and the Brazilian Pediatrics Society ${ }^{26}$. The age was set at six months because that is when most children reach a development stage with physiological and neurological maturity of the organs, as well as global and oral motor development. The digestive enzymes are produced in a sufficient amount, which enables the children to receive foods other than breast milk ${ }^{11}$.

Delaying too much to introduce the complementary food is not recommended (considering only the aspect of prematurity), neither starting early, before the child is prepared for it. Thus, before considering whether to introduce complementary food, it is important to consider both the adjusted age and the signs of readiness to accept foods - i.e., decreased extrusion of the tongue, neck control (necessary to safely swallow solid foods), and whether the baby can remain seated with support ${ }^{12}$. In this study, most of the children started having complementary foods before the six months (adjusted age) because they had neck control and signs of readiness for feeding. Two children (5.12\%) did not have full neck control, yet they started complementary feeding by indication from the professional team.

The early introduction of food can cause an increase in morbimortality, due to the risk of food contamination, early weaning, interference with nutrient absorption, and predisposition to allergic reactions, such as asthma, atopic dermatitis, and food allergies. On the other hand, the late introduction of food is associated with growth deficits and the risk of micronutrient, energy, and protein deficiency ${ }^{12}$.

The coordination of the chewing movements resulting from the stimulation of food present in the oral cavity is very adaptative in children. However, it becomes more difficult as it gets late. Such a difficulty is mentioned by the World Health Organization ${ }^{18,27}$.

In a literature review, the authors stated that premature children, especially those with very low birth weight, are more prone to presenting feeding problems in the early stages of life and childhood when compared with full-term children. It is strictly recommended that these children's feeding be monitored in an intervention program with specialized professionals, to promote adequate feeding development, as well as ensure an adequate growth ${ }^{28}$.

Regarding motor and language development, it was statistically observed that a great part of the infants had typical development. However, four children did not reach all the development milestones; they had cerebral palsy due to their clinical condition, which made them dependent on family care for the activities of daily living, besides needing rehabilitation from 
speech-language-hearing therapy, physical therapy, and occupational therapy. Another four children had slowed development, although they reached the motor and language development milestones analyzed when considering the adjusted age (Figure 4). The specialized peri- and neonatal assistance, with human and technological resources adequate to care for high-risk newborns, as well as the outpatient follow-up, made it possible to instruct the parents/guardians regarding the necessary stimulations at home. It also enabled alterations and difficulties to be early detected, favoring adequate development. A study was analyzed, which also found low neurodevelopment impairment rates in premature children ${ }^{29}$.

In the reviewed literature, there were studies indicating development impairment in preterm children. With the adjusted age, a study stated that $39 \%$ of the premature children assessed at four months old with the Alberta Infant Motor Scale presented a high risk of motor development delay, as well as $33 \%$ of the premature children assessed at eight months old ${ }^{30}$. Scholars analyzed, with the Denver Scale-II, the motor performance of preterm infants with and without bronchopulmonary dysplasia and observed that the children with bronchopulmonary dysplasia had greater neuropsychomotor development delay when compared with those who did not have it ${ }^{31}$.

Researchers assessed the NPMD of 67 children up to school age with Griffiths Mental Development Scales. In the first assessment (mean age: 29.7 months), the mean global development quotient (GDQ) was 95.9 $(7.9 \%$ with $\mathrm{GDQ} \leq 80)$. In the last assessment, (mean age: 65.8 months), the mean GDQ was 100.5 (5.2\% with $\mathrm{QDG} \leq 80$ ). The most frequent neurodevelopmental disorders were attention-deficit/hyperactivity disorder, language disorder, and learning disorder ${ }^{32}$. Another study used Bayley-III to assess premature children in the outpatient follow-up - $4(6.9 \%)$ had cognitive alterations; 4 (6.9\%), motor alterations; 17 (29.3\%), language alterations; $16(27.6 \%)$, socioemotional alterations; and $22(37.9 \%)$, adaptive behavior alterations ${ }^{33}$.

In a literature review, the authors found 29 articles approaching the effect of prematurity on language development. Four studies investigated the association between risk factors and language development problems. One of the studies assessed schoolchildren and associated the Apgar scores with a specific language disorder. Early follow-up and intervention were unanimously recommended ${ }^{34}$.
When the PTNB are compared with the FTNB, they are at higher risks of neuromotor disorders and growth difficulties. In case they present signs suggestive of developmental delay, they must be referred to specialized institutions ${ }^{35}$.

The neonatal hearing screening (NHS) is meant to early identify hearing loss. Performing it is recommended, due to the various risk indicators for hearing loss in the PTNB who stayed in neonatal ICU ${ }^{17}$.

Besides electrophysiological examinations, such as the otoacoustic emissions (infant hearing screening test), and the brainstem auditory evoked potentials (BAEP), it is recommended that the behavioral auditory assessment be made with the "auditory kit" - which comprises emitters whose intensity and sound spectrum are known. The expected responses are the startle, the cochlear-palpebral reflex, and sound localization with varied laterality ${ }^{12}$.

This study observed that a great part of the PTNB had auditory development and hearing within normality standards, according to the OAE, auditory screening, and BAEP - which agrees with the findings in the reviewed literature, whose rates were higher than $90 \%{ }^{36,37}$. An audiological monitoring study revealed that all the babies with normal NHS rates and risk indicators for hearing loss gave adequate responses in the behavior observation audiometry and presented cochlear-palpebral reflex ${ }^{38}$. All the individuals in this study had the risk indicators for hearing loss described in the literature, such as staying in the intensive care unit for more than five days, using mechanical ventilation, taking ototoxic drugs, having hyperbilirubinemia, scoring 0 to 6 in the five-minute Apgar, having weight lower than $1,500 \mathrm{~g}$, and being small for the gestational age $^{12}$.

The risk factors for growth and development alterations were present in all participants of the research. Hence, they were referred for outpatient follow-up with a multiprofessional team, to which 29 out of the 39 children adhered $(74.3 \%)$. The rehabilitation referral rate was $20.5 \%$ (eight children), who needed individual care in physical therapy, speech-language-hearing therapy, and occupational therapy. These children had developmental delays and signs of cerebral palsy. A study evidenced cerebral palsy in $9.5 \%$ of extremely preterm children (with less than 30 weeks of GA) ${ }^{39}$.

In the reviewed literature, only one study was found approaching preterm children's adherence to outpatient follow-up. That study confirmed that the global evasion rate throughout the seven years was $43.7 \%$ 
- higher rates than those found in the present study. However, the follow-up lasted longer. There were significant differences between the evasion and follow-up groups regarding the mothers' age and schooling level. It was identified that the reasons for the evasions were related to socioeconomic aspects and the health care service's organization ${ }^{40}$.

The tests used to assess the child development milestones were chosen because of their validity and easy administration. Moreover, they could be used in the different levels of health care, such as screening to detect alterations, referrals for specialized assessment, and early intervention. Nonetheless, the literature review and comparison were limited. As for the complementary feeding of premature children, there is no consensus concerning the time to begin; few studies approach this issue. Thus, further studies on these subjects are recommended.

The work of speech-language-hearing therapy with PTNB aims to promote breastfeeding, assessment, follow-up, and intervention whenever there are feeding, hearing, and language alterations. Therefore, the importance of the speech-language-hearing professional in hospital and/or outpatient services is highlighted, as they monitor the neurodevelopment of these individuals.

\section{CONCLUSION}

Most of the children in the study were discharged from the hospital on breastfeeding - the exclusive breastfeeding lasted four months on average, and the mixed milk feeding lasted six months on average.

In this study, the premature children, followed up until two years old, had low neuropsychomotor impairment rates. The rehabilitation referral rates for speech-language-hearing therapy, physical therapy, and occupational therapy were $20.5 \%$.

\section{REFERENCES}

1. Lemos RA, Frônio JS, Neves LAT, Ribeiro LC. Estudo da prevalência de morbidades e complicações neonatais segundo o peso ao nascimento e a idade gestacional em lactentes de um serviço de follow-up. Rev. APS. 2010;13(1):277-90.

2. Fijinaga $\mathrm{Cl}$, Scochi CGS, Santos $\mathrm{CB}$ dos, Zamberlan NE, Leite AM. Validação do conteúdo de um instrumento para avaliação da prontidão do prematuro para início da alimentação oral. Rev. Bras. Saúde Mater. Infant. 2008;8(4):391-9.
3. Willumsen DK, Guastalla R. Características específicas da anatomofisiologia do sistema estomatognático na prematuridade. In: Carvalho MR, Gomes CF (eds). Amamentação - Bases científicas. 4aㅡ ed. Rio de Janeiro: Guanabara Koogan; 2017. p. 330-8.

4. Willumsen DK, Guastalla R. Características específicas da anatomofisiologia do sistema estomatognático na prematuridade. In: Carvalho MR, Gomes CF (eds) Amamentação - Bases científicas. 4. ed. Rio de Janeiro: Guanabara Koogan, 2017. p. 330-8.

5. Hernandez AM. Atuação fonoaudiológica em neonatologia: uma proposta de intervenção. In: Andrade CF (ed). Fonoaudiologia em berçário normal e de risco. São Paulo, Lovise. 1996. p. 1-37.

6. Nascimento MBR, Issler H. Breastfeeding: making the difference in the development, health and nutrition of term and preterm newborns. Rev Hosp Clin Fac Med Sao Paulo. 2003;58(1):49-60.

7. Mont MMF, Botega MBS, Lima MCMP, Kubota SMP. Demand for speech therapy intervention in neonatal unit of a teaching hospital. Rev. CEFAC. 2013;15(6):1540-51.

8. Ferraz ST, Frônio JS, Neves LAT, Demarchi RS, Vargas ALA, Ghetti FF et al. Programa de follow up de recém nascidos de alto risco: relato de experiência de uma equipe interdisciplinar. Rev. APS. 2010;13(1):133-9.

9. Varandas CPM, Campos LG, Motta AR. Adesão ao tratamento fonoaudiológico segundo a visão de ortodontistas e odontopediatras. Rev. soc. bras. fonoaudiol. 2008;13(3):233-9.

10. Pivante $\mathrm{CM}$, Medeiros AMC. Intervenções fonoaudiológicas no aleitamento materno junto às mães de paridade zero. Mundo Saúde. 2006;30(1):87-95.

11. Schalka MMS, Buelau PJ, Buelau MIM. Alimentação complementar gradativa: aspectos importantes da função mastigatória. In: Takaoka L, Coutinho L, Weiler R (eds). Odontopediatria: a transdisciplinariedade na saúde integral da criança. Barueri: Manole, 2015. p. 189-202.

12. BRASIL. Ministério da Saúde. Manual do Método Canguru - Seguimento Compartilhado entre Atenção Hospitalar e Atenção Básica. Brasília - DF. 2015.

13. BRASIL. Ministério da Saúde. Portaria no 693, de 5 de julho de 2000. Normas de Orientação para a 
Implantação do Método Canguru. Diário Oficial da União, Poder Executivo, Brasília, 2000.

14. World Health Organization. Public health aspects of low birth weight: third report of the Expert Committee on Maternal and Child Health. Geneva: World Health Organization; 1961. (WHO Technical Reporter Service, 217)

15. Frankenburg WK, Dodds J, Archer $P$, Shapiro $H$, Bresnick B. DENVER II: training manual. 2nd ed. Denver, USA: Denver Developmental Materials; 1992.

16. Gesell A. A criança de 0 a 5 anos. 4a edição, São Paulo: Martins Fontes, 1996.

17. BRASIL. Ministério da Saúde. Saúde da Criança: acompanhamento do crescimento e desenvolvimento infantil. Série Cadernos de Atenção Básica, n. 11, 2002.

18. Pan American Health Organization/World Health Organization (PAHO/WHO). Guiding principles for complementary feeding of the breastfed child. Division of health promotion and protection. Food and Nutrition Program. Washington/Geneva: Pan American Health Organization/ World Health Organization, 2003.

19. Dancey C, Reidy J. Estatística sem matemática para psicologia: usando SPSS para Windows. Porto Alegre, Artmed, 2006.

20. Basso CSD, Arroyo MAS, Saes MABF, Beani L, Maia $A B$, Lourenção LG. Breastfeeding rate and speech-language therapy in the Kangaroo Method. Rev. CEFAC. 2019;21(5):e11719.

21. Antunes VP, Berwig LC, Steidi SEM, Weinmann RM. Influence of the endotracheal tube on the feeding performance and signs of stress in preterm infants. Distúrb Comum. 2014;26(3):569-75.

22. Gomes ALM, Balaminut T, López SB, Pontes KAES, Scochi CGS, Christoffel MM. Aleitamento materno de prematuros em hospital amigo da criança: da alta hospitalar ao domicílio. Rev. RENE. 2017;18(6):810-17.

23. Leite $P$, Freire $A$, Ribeiro $S$, Jeferson $G$. Breastfeeding incidence at discharge of the third stage of the kangaroo method of maternity Ana Braga. Amazonia Health Science Journal. 2017;1(1):45-68.

24. Méio BDDB, Vilela LD, Gomes Júnior SCS, Tovar CM, Moreira MEL. Breastfeeding of preterm newborn infants following hospital discharge: follow-up during the first year of life. Ciênc. saúde coletiva. 2018;23(7):2403-12.
25. Freitas BAC, Lima LM, Carlos CFLV, Priore SE, Franceschin SCC. Duration of breastfeeding in preterm infants followed at a secondary referral service. Rev Paul Pediatr. 2016;34(2):189-96.

26. Sociedade Brasileira de Pediatria. Posição da Sociedade Brasileira de Pediatria diante do Guia de Alimentação do Ministério da Saúde. Rio de Janeiro, RJ: A Sociedade; 2019.

27. Sarrafpour B, Swain MLIQ, Zoellner H. Tooth eruption results from bone remodeling driven by bite forces sensed by soft tissue dental follicles: a finite element analysis. Plos One. 2013;8(3):1-18.

28. Pagliaro CL, Bühler KEB, Ibidi SM, Limongi SCO. Dietary transition difficulties in preterm infants: critical literature review. J Pediatr. 2016;92(1):7-14.

29. Synnes A, Hicks M. Neurodevelopmental outcomes of preterm children at school age and beyond. Clin Perinatol. 2018;45(3)393-408.

30. Righi NC, Martins FK, Hermes L, Rosa KM, Böck THO, Trevisan CM. Influência da correção da idade na detecção de riscos no desenvolvimento motor de prematuros. Saúde e Pesqui. 2017;10(3):417-21 .

31. Silva LV, Araujo LB, Azevedo VMGO. Assessment of the neuropsychomotor development in the first year of life of premature infants with and without bronchopulmonary dysplasia. Rev Bras Ter Intensiva. 2018;30(2):174-80.

32. Ferreira S, Fontes N, Rodrigues L, Gonçalves C, Lopes MM, Rodrigues N. Desenvolvimento psicomotor de grandes prematuros. Acta Pediatr Port. 2013;44(6):319-24.

33. Fernandes LV, Goulart AL, Santos AM, Barros MC, Guerra CC, Kopelman BI. Neurodevelopmental assessment of very low birth weight preterm infants at corrected age of 18-24 months by Bayley III scales. J Pediatr. 2012;88(6):471-8.

34. Carniel CZ, Furtado MCC, Vicente JB, Abreu RZ, Tarozzo RM, Cardia SETR et al. Influence of risk factors on language development and contributions of early stimulation: an integrative literature review. Rev. CEFAC. 2017;19(1):109-18.

35. Fontenele CC, Silvino FF, Terra LCT, Alencar MA, Pinto SM, Ferreira SMP. Intervenção precoce. In: Lima CLA, Fonseca LF (eds). Paralisia Cerebral. Rio de Janeiro: Guanabara Koogan, 2004. p. 321-33.

36. Biscegli TS, Bertoni A, Belucio IS, Marcos JMO, Matias TY, Cid FB. Triagem auditiva neonatal: estudo dos neonatos de um hospital-escola do interior do Estado de São Paulo. Pediatr. mod. 2015;51(6):214-9. 
37. Silvia AA, Bento DV, Silvia LNFB. Occurrence of indicators for hearing loss in a center of health of Rio Grande do Sul. Audiol., Commun. Res. 2018;23:e1919.

38. Carneiro CS, Pereira MCCS, Lago MRR. Audiological monitoring of infants with risk indicators for hearing loss. Distúrb. Comun. 2016;28(3):512-22.

39. Serenius F, Ewald U, Farooqi A, Fellman V, Hafström M, Hellgren $K$ et al. Neurodevelopmental outcomes among extremely preterm infants 6.5 years after active perinatal care in Sweden. JAMA Pediatr. 2016;170(10):954-63.

40. Gontijo ML, Cardoso AA, Dittz ES, Magalhães LC. Evasão em ambulatório de seguimento do desenvolvimento de pré-termos: taxas e causas. Cad Bras Ter Ocu. 2018;26(1):73-83. 